\section{International Scientific Journal Theoretical \& Applied Science}

p-ISSN: 2308-4944 (print) e-ISSN: 2409-0085 (online)

Year: $2014 \quad$ Issue: 12 Volume: 20

Published: $30.12 .2014 \quad \underline{\text { http://www.T-Science.org }}$

SECTION 6. Metallurgy and energy.
Bazartai Alimbayevich Alimbayev doctor of technical sciences,

Professor of the department «Building materials and constructions»

M.Kh. Dulaty Taraz State University, Kazakhstan

Bauyrzhan Zharkynbekovich Manapbayev candidate of technical sciences, associate professor of the Department of «Oil and gas engineering »

M.Kh. Dulaty Taraz State University, Kazakhstan jiboj@mail.ru

Zhanna Bazartayevna Alimbayeva Senior lecturer of the department «Architecture and construction production»

M.Kh. Dulaty Taraz State University, Kazakhstan

Raushan Janatovna Djanuzakova

Lecturer of the department «Automation and telecommunication»

M.Kh. Dulaty Taraz State University, Kazakhstan

\title{
ABOUT ONE MECHANISM OF DEVELOPMENT OF CORROSION IN STEEL DESIGNS
}

Abstract: In this paper we propose a mechanism of corrosion in the steel construction elements. Presents the results of electron-microscopic examination and chemical analyses of samples from the corroded surfaces of steel structures.

Key words: corrosion, ferromagnetic domains, Lorentz's force, chemical analyses.

Language: Russian

Citation: Alimbayev BA, Manapbayev BZ, Alimbayeva ZB, Djanuzakova RJ (2014) ABOUT ONE MECHANISM OF DEVELOPMENT OF CORROSION IN STEEL DESIGNS. ISJ Theoretical \& Applied Science 12 (20): 111-118. doi: http://dx.doi.org/10.15863/TAS.2014.12.20.25

\section{ОБ ОДНОМ МЕХАНИЗМЕ РАЗВИТИЯ КОРРОЗИИ В СТАЛЬНЫХ КОНСТРУКЦИЯХ}

Аннотация: В работе предложен один из механизмов развития коррозии в элементах стальных конструкций. Представлены результаты электронно-микроскопических исследований и химических анализов, образцов из корродированных поверхностей стальных конструкций.

Ключевые слова: коррозия, ферромагнитные домены, сила Лоренца, химические анализы.

Процесс коррозии металлов и борьба с ней является одной из наиболее сложных направлений. Предложенные до этого времени механизмы развития коррозии $[1,2,3,4]$, хотя и были обоснованны на высоком техническом уровне и описаны с учетом основных факторов развития коррозии, не являются совершенными и не смогут полностью раскрыть механизм развития коррозии. Недостатком всех предложенных механизмов является не учет того факта, что элементы стальных конструкций являются ферромагнитными материалами, в которых в нормальных условиях существуют доменные структуры. Это указывает на то, что до этого времени, никто не учитывал ферромагнитные свойства сталей при изучении коррозии, и это было недоработкой исследователей.
В отличие от существующих механизмов развития коррозии нами $[5,6]$ предложен один из вариантов механизма развития коррозии в элементах стальных конструкций находящихся в водной среде, с учетом их ферромагнитных свойств. Для исследований были отобраны образцы из элементов стальных конструкций гидроузла расположенного на p. Acca 10 км южнее г.Тараз в Жамбылской области и проведены электронно-микроскопические исследования образцов в лаборатории «Наноинженерные методы исследований» Таразского государственного университета им. М.Х.Дулати. Образцы были выбраны в местах, где коррозия была наиболее развита.

Результаты исследования [7] под растровым электронным микроскопом JSM-7500F показали, что на корродированных поверхностях образцов имеются множество трещин (рис.1). Трещины 
имеют микро и нано размеры, и образуют сложные формы. Они появляются от нагрузок и ударов, но дальнейшее их развитие связано с коррозионными явлениями и адсорбцией среды. Также на рисунке 1 видно, что образовавшиеся на

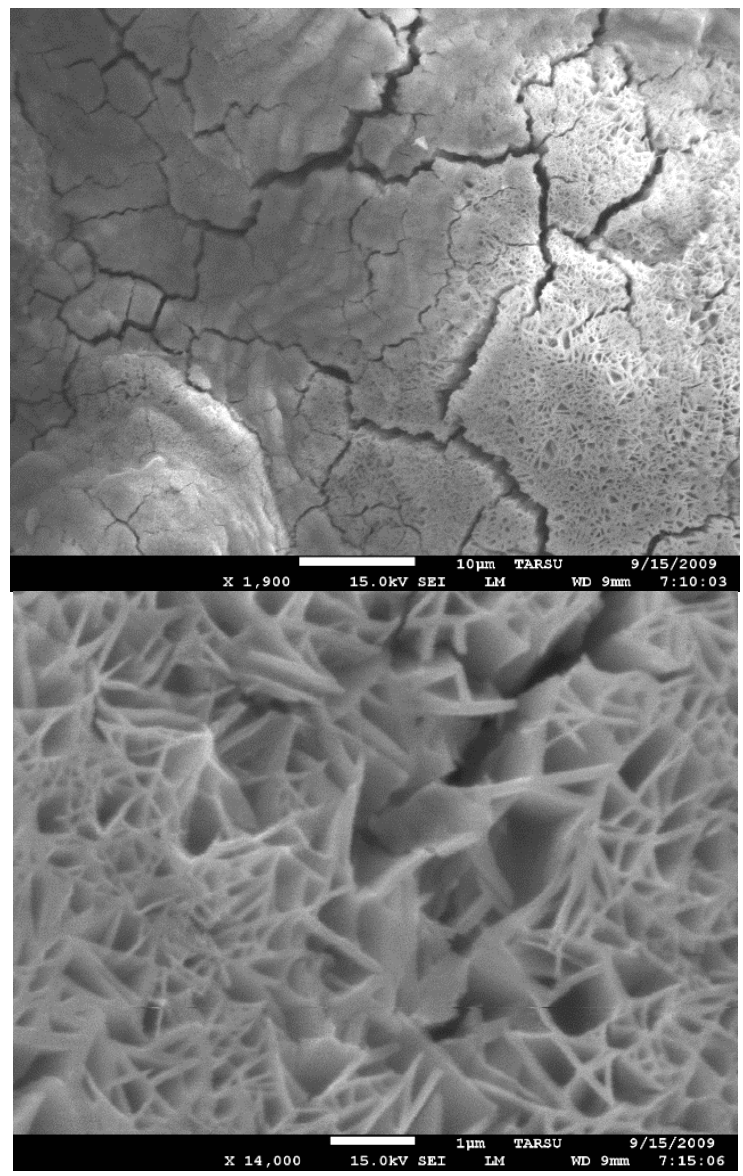

поверхностях трещин продукты коррозии, от повторных нагрузок и напряжений опять растрескиваются по прежним местам трещин. Механизм заключается в следующем.

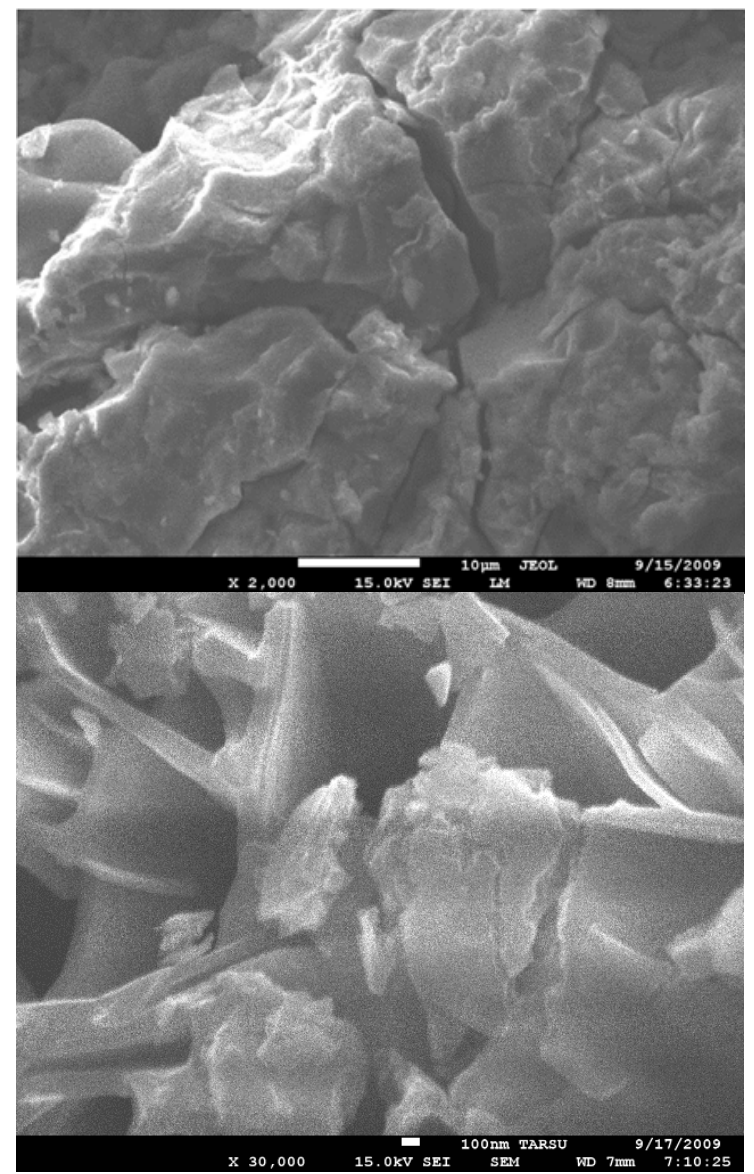

Рисунок 1 - Снимки корродированной поверхности образца электронным микроскопом JSM-7500F.

Адсорбция коррозионно-активных веществ из среды влияет на уменьшение сродство поверхностных атомов поверхностей стальных конструкций. Под действием различных нагрузок и ударов на ослабленных адсорбцией поверхностях стальных конструкций появляются трещины.

Элементы стальных конструкций являются ферромагнитными материалами, состоящие из доменных структур [8]. В свою очередь, появившиеся трещины и дефекты повреждают доменные структуры в ферромагнитных материалах, в которых при повреждении изменяются магнитные характеристики.

При нарушении доменной структуры стали, происходит разделение доменов на части (рис.2), из-за этого в концах трещин начинают создаваться магнитные полюса [9], а между ними действовать магнитное поле.

Как известно [10], на заряды движущихся в магнитном поле, созданном от нарушенных структур ферромагнитных доменов, то есть между краями трещин, действует сила Лоренца, описываемая по формуле

$$
\vec{F}_{Л}=q \cdot[\vec{v} \cdot \vec{B}]
$$

В обычной водной среде присутствуют молекулы воды $\mathrm{H}_{2} \mathrm{O}$, ионы гидроксония $\mathrm{H}_{3} \mathrm{O}^{+}$и гидроксила $\mathrm{OH}^{-}$. Перемещение ионов в воде происходит по особому, так называемому эстафетному механизму [11], который состоит в том, что между ионами гидроксония $\mathrm{H}_{3} \mathrm{O}^{+}$и молекулами воды, а также между молекулами воды и ионами $\mathrm{OH}^{-}$непрерывно происходит обмен ионами водорода $\mathrm{H}^{+}$. Под действием силы Лоренца [12] происходит разделение ионов с разными знаками, это способствуют дополнительному появлению между краями трещин ионов водорода $\mathrm{H}^{+}$и гидроксил-ионов $\mathrm{OH}^{-}$, то есть диссоциации воды. 


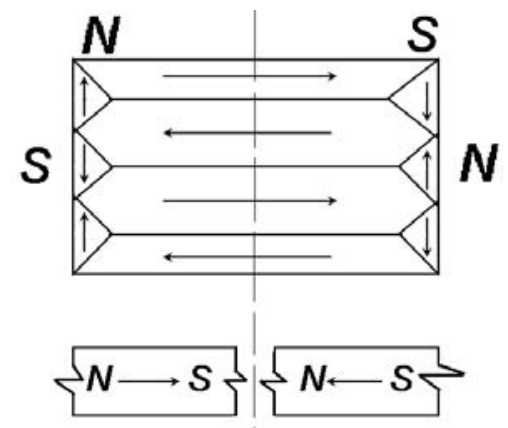

Рисунок 2 - Схема разрушения доменной структуры.
Кроме этого, сила Лоренца играет важную роль при абсорбции частиц из водной среды. Особенно, интенсивно будут поглощаться трещинами положительные ионы по направлению силы Лоренца. На ионы $q$ движущиеся с определенной скоростью $v$ в магнитном поле $B$ действует сила Лоренца $F_{Л}$, которая старается повернуть ионы в перпендикулярном направлении (рис.3). За счет силы Лоренца действующем в этом магнитном поле ионы водорода $\mathrm{H}^{+}$и гидроксил-ионы $\mathrm{OH}^{-}$ будут притягиваться к краям трещины как к полюсам магнита (рис.4).

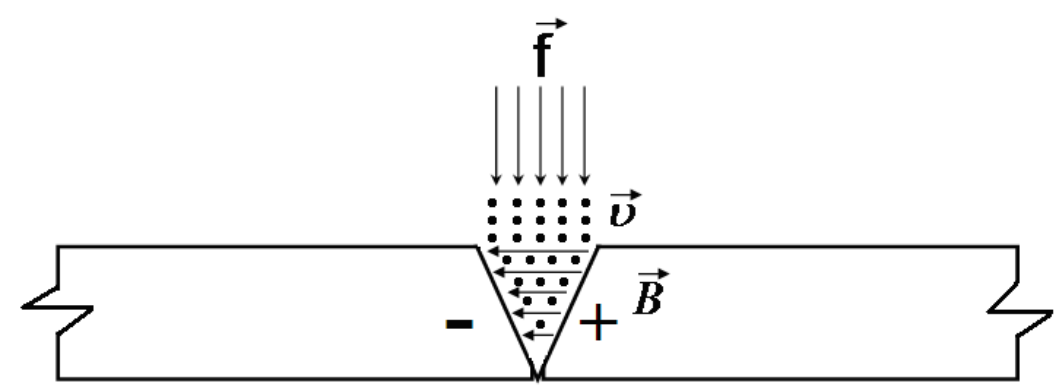

Рисунок 3 - Направления силы Лоренца, скорости движения ионов и магнитного поле касательно трещины в доменной структуре.

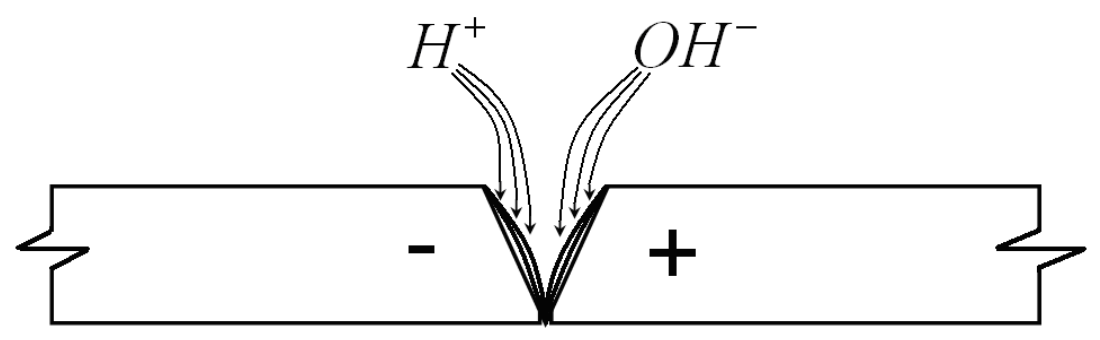

Рисунок 4 - Наполнение трещины доменной структуры ионами $\mathrm{H}^{+}$и $\mathrm{OH}^{-}$.

После прохождения физического процесса начинается химический процесс, т. е. реализуется этап развития трещин - их коррозионное зарождение. В трещине из-за недостатка кислорода активно протекает реакция

$$
\mathrm{Fe} \rightarrow \mathrm{Fe}^{2+}+2 \mathrm{e}^{-} ; \mathrm{Fe}^{2+}+2 \mathrm{OH}^{-} \rightarrow \mathrm{Fe}(\mathrm{OH})_{2} ; 2 \mathrm{H}^{+}+2 \mathrm{e}^{-} \rightarrow \mathrm{H}_{2},
$$

В результате химической реакции образуется гидроксид железа (II), который создает пленку. Она наполняет образовавшиеся трещины (рис.5), что приводит к замедлению или завершению выше приведенных физических и химических процессов, то есть к пассивации металла. Также, в данном случае активно восстанавливается и абсорбируется водород. За счет силы Лоренца к вершине трещины сильно притягиваются и абсорбируются только ионы водорода $\mathrm{H}^{+}$, так как они имеют положительный заряд $q$ ионов. 


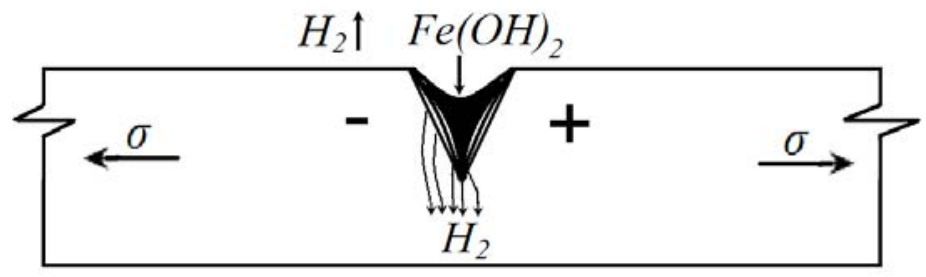

\section{Рисунок 5 - Образованная пленка из гидроксида железа (II) в трещине и восстановление ионов} водорода.

В трещине ионы водорода $\mathrm{H}^{+}$ восстанавливаются, и по двум схемам удаляются из трещины, то есть часть абсорбируется в структуру металла через вершину трещины, а остальная часть удаляется как газ в атмосферу:

$$
\begin{aligned}
4 \mathrm{H}^{+}+4 \mathrm{e} \rightarrow \quad & \rightarrow \mathrm{H}_{2} \uparrow \text { (в атмосферу) } \\
& \rightarrow 2 \mathrm{H} \text { (абсорбируется металлом) }
\end{aligned}
$$

Часть водорода, попавшая в металл, диффундирует по его объему в зону максимальных трехосных напряжений, которая находится перед вершиной трещины. Поступивший в эту зону водород, ускоряет процесс коррозионного подрастания трещины, так как наводороживание металла существенно снижает его коррозионную стойкость (рис.5).

На внешней поверхности оксидной пленки, доступной растворенному кислороду в воде, гидроксид железа (II) окисляется до гидроксида железа (III):

$$
4 \mathrm{Fe}(\mathrm{OH})_{2}+2 \mathrm{H}_{2} \mathrm{O}+\mathrm{O}_{2} \rightarrow 4 \mathrm{Fe}(\mathrm{OH})_{3}
$$

В дальнейшем происходит частичная дегидратация гидроксида железа (III). Данная реакция описана в следующей формуле:

$$
\mathrm{Fe}(\mathrm{OH})_{3}-\mathrm{H}_{2} \mathrm{O} \rightarrow \mathrm{FeO}(\mathrm{OH})
$$

Стальные конструкции работают в постоянных условиях переменных нагрузок (напряжений). При малейшем механическом воздействии - увеличение величин механических напряжении или простое механическое воздействии на элементы стальных конструкций, ранее отмеченные трещины раскрываются, и возобновляется процесс коррозии.

Для подтверждения предложенного механизма развития коррозии был проведен химический анализ образцов и продуктов коррозии, взятых из корродированных поверхностей металлических конструкций Ассинского гидроузла. Были проведены: рентгеноспектральный микроанализ, термический анализ, рентгенодифрактометрический анализ продуктов коррозии металлических конструкций в лабораториях института геологических наук им. К.И. Сатпаева (г. Алматы).

Рентгеноспектральный микроанализ образцов и продуктов коррозии проводился с использованием энергодисперсионного спектрометра INCA ENERGY фирмы «OXFORD INSTRUMENTS» (Англия), установленного на приборе электронно-зондовый микроанализатор марки Superprobe 733 фирмы «JEOL» Ltd. (Япония) при ускоряющем напряжении 25 кВ и токе зонда 25 мА.

Результаты

рентгеноспектрального микроанализа приведены в таблицах 1 и 2 для образца взятого из корродированной поверхности сегментного затвора Ассинского гидроузла, а также в таблицах 3 и 4 для образца из продуктов коррозии. На основе таблиц 1 и 3 построены спектрограммы (рис. 6).

Таблица 1

Химический состав образца взятого из корродированной поверхности (все результаты в весовых \%)

\begin{tabular}{|l|c|c|c|c|c|c|c|c|c|c|}
\hline Спектр & $\mathrm{O}$ & $\mathrm{Mg}$ & $\mathrm{Al}$ & $\mathrm{Si}$ & $\mathrm{S}$ & $\mathrm{Cl}$ & $\mathrm{K}$ & $\mathrm{Ca}$ & $\mathrm{Fe}$ & Итог \\
\hline Спектр 1 & 47,48 & 0,14 & 0,01 & 0,12 & 0,37 & 0,26 & 0,07 & 0,21 & 51,34 & 100,00 \\
\hline Спектр 2 & 40,08 & 1,33 & 0,20 & 0,61 & 0,18 & 0,04 & 0,15 & 0,46 & 56,94 & 100,00 \\
\hline Спектр 3 & 37,05 & 0,09 & 0,00 & 0,14 & 0,34 & 0,93 & 0,05 & 0,25 & 61,16 & 100,00 \\
\hline Среднее & 41,54 & 0,52 & 0,07 & 0,29 & 0,29 & 0,41 & 0,09 & 0,31 & 56,48 & 100,00 \\
\hline
\end{tabular}

Таблица 2

Химический состав образца взятого из корродированной поверхности (все результаты в соединениях 


\begin{tabular}{|l|c|c|c|c|c|c|c|c|c|c|}
\hline Спектр & $\mathrm{Na}_{2} \mathrm{O}$ & $\mathrm{MgO}$ & $\mathrm{Al}_{2} \mathrm{O} 3$ & $\mathrm{SiO}_{2}$ & $\mathrm{SO}_{3}$ & $\mathrm{Cl}$ & $\mathrm{K}_{2} \mathrm{O}$ & $\mathrm{CaO}$ & $\mathrm{Fe}_{2} \mathrm{O}_{3}$ & Итог \\
\hline Спектр 1 & 0,79 & 0,33 & 0,05 & 0,41 & 1,46 & 0,40 & 0,13 & 0,44 & 95,98 & 100,00 \\
\hline Спектр 2 & 0,51 & 3,02 & 0,54 & 1,79 & 0,58 & 0,06 & 0,23 & 0,82 & 92,46 & 100,00 \\
\hline Спектр 3 & 0,72 & 0,14 & 0,00 & 0,39 & 1,08 & 1,17 & 0,08 & 0,44 & 95,98 & 100,00 \\
\hline Среднее & 0,67 & 1,16 & 0,20 & 0,86 & 1,04 & 0,54 & 0,15 & 0,57 & 94,81 & 100,00 \\
\hline
\end{tabular}

Таблица 3

Химический состав образца из продуктов коррозии (все результаты в весовых \%)

\begin{tabular}{|l|c|c|c|c|c|c|c|c|c|c|c|c|c|c|c|}
\hline Спектр & $\mathrm{O}$ & $\mathrm{Na}$ & $\mathrm{Mg}$ & $\mathrm{Al}$ & $\mathrm{Si}$ & $\mathrm{S}$ & $\mathrm{K}$ & $\mathrm{Ca}$ & $\mathrm{Cr}$ & $\mathrm{Mn}$ & $\mathrm{Fe}$ & $\mathrm{Zn}$ & $\mathrm{As}$ & Рb & Итог \\
\hline Спектр 1 & 29,48 & 0,35 & 0,56 & 0,67 & 2,83 & 0,52 & 0,19 & 4,04 & 0,15 & 0,28 & 58,93 & 0,15 & 0,44 & 1,41 & 100,00 \\
\hline Спектр 2 & 28,13 & 0,29 & 0,50 & 0,81 & 3,07 & 0,37 & 0,18 & 4,59 & 0,02 & 0,35 & 59,86 & 0,19 & 0,49 & 1,15 & 100,00 \\
\hline Спектр 3 & 29,54 & 0,30 & 0,53 & 0,65 & 2,80 & 0,26 & 0,21 & 4,50 & 0,03 & 0,29 & 60,18 & 0,00 & 0,27 & 0,46 & 100,00 \\
\hline Среднее & 29,05 & 0,31 & 0,53 & 0,71 & 2,90 & 0,38 & 0,19 & 4,38 & 0,07 & 0,31 & 59,66 & 0,10 & 0,40 & 1,01 & 100,00 \\
\hline
\end{tabular}

Химический состав образца из продуктов коррозии (все результаты в соединениях \%)

Таблица 4

\begin{tabular}{|l|c|c|c|c|c|c|c|c|c|c|c|c|c|c|}
\hline Спектр & $\mathrm{Na}_{2} \mathrm{O}$ & $\mathrm{MgO}$ & $\mathrm{Al}_{2} \mathrm{O}_{3}$ & $\mathrm{SiO}_{2}$ & $\mathrm{SO}_{3}$ & $\mathrm{~K}_{2} \mathrm{O}$ & $\mathrm{CaO}$ & $\mathrm{Cr}_{2} \mathrm{O}_{3}$ & $\mathrm{MnO}$ & $\mathrm{Fe}_{2} \mathrm{O}_{3}$ & $\mathrm{ZnO}$ & $\mathrm{As}_{2} \mathrm{O}_{3}$ & РbО & Итог \\
\hline Спектр 1 & 0,51 & 1,00 & 1,36 & 6,50 & 1,38 & 0,24 & 5,99 & 0,24 & 0,38 & 79,97 & 0,19 & 0,61 & 1,63 & 100,00 \\
\hline Спектр 2 & 0,40 & 0,87 & 1,60 & 6,87 & 0,97 & 0,22 & 6,66 & 0,03 & 0,47 & 79,69 & 0,24 & 0,67 & 1,29 & 100,00 \\
\hline Спектр 3 & 0,44 & 0,95 & 1,33 & 6,46 & 0,69 & 0,27 & 6,68 & 0,05 & 0,39 & 81,87 & 0,00 & 0,38 & 0,54 & 100,00 \\
\hline Среднее & 0,45 & 0,94 & 1,43 & 6,61 & 1,01 & 0,24 & 6,44 & 0,11 & 0,41 & 80,51 & 0,13 & 0,55 & 1,15 & 100,00 \\
\hline
\end{tabular}

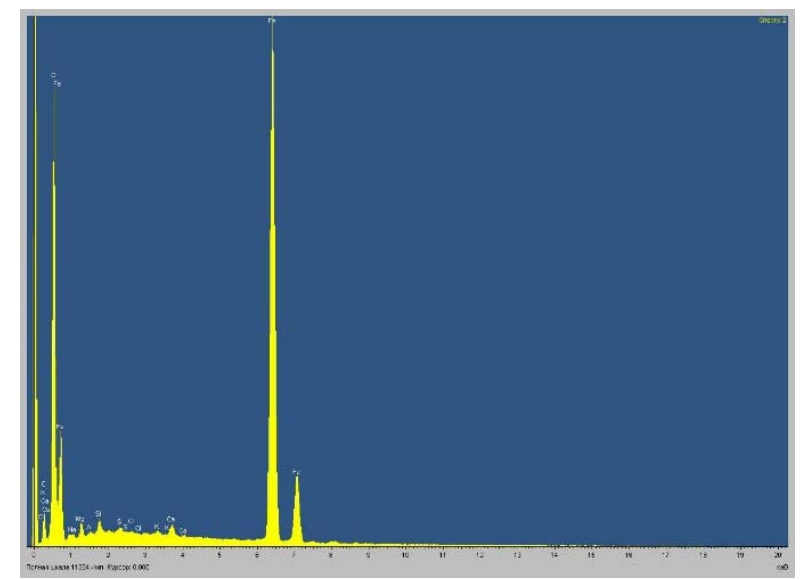

a

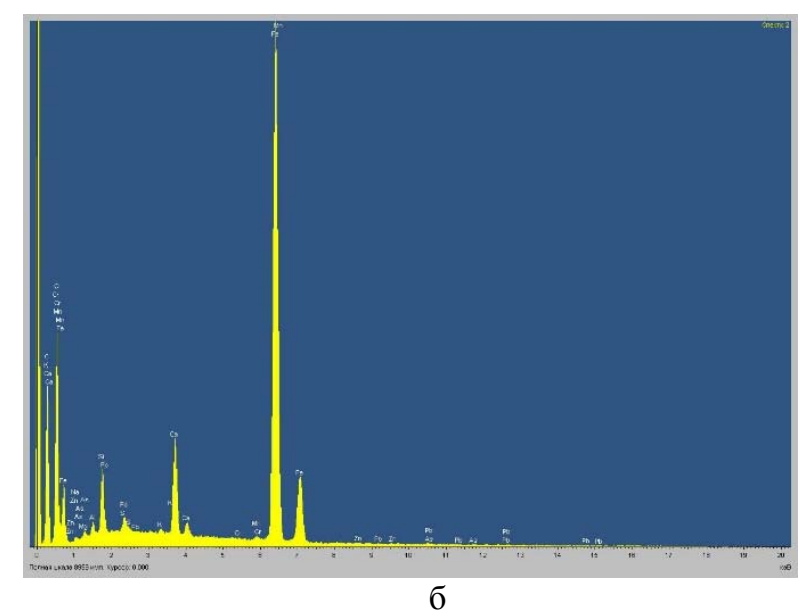

Рисунок 6 - Спектрограммы образца взятого из корродированной поверхности металла (а) и образца из продуктов коррозии (б).

Из таблиц 3 и 4 видно, что в составе образца имеется большое количество гидроксида $\mathrm{Fe}_{2} \mathrm{O}_{3}$. Но его присутствие только косвенно объясняет предложенный механизм развития коррозии, хотя гидроксид $\mathrm{Fe}_{2} \mathrm{O}_{3}$ является продуктом коррозии и должен обязательно присутствовать в данных образцах, но необходимо определить в исследуемых образцах гидроксид железа (II) $\mathrm{Fe}(\mathrm{OH})_{2}$ и гидроксид железа (III) $\mathrm{Fe}(\mathrm{OH})_{3}$. Поэтому проведен термический анализ образца из продуктов коррозии взятого из корродированной поверхности металлических конструкций Ассинского гидроузла и определено количественное содержание их в пробе. Наряду с этим получены результаты по содержанию в навеске разноуровневых гидратных $\left(\mathrm{H}_{2} \mathrm{O}\right.$ и $\left.\mathrm{OH}\right)$ включений.

Используемый метод основан на регистрации прибором изменений термохимических и физических параметров вещества, которые могут быть вызваны при его нагревании. При непрерывно возрастающей температуре печи, термоустановка фиксирует изменение энтальпии (ДТА) системы и термогравиметрические показания навески.

Термохимическое состояние пробы описываются кривыми: Т (температурной), ДТА (дифференциальной термоаналитической), TG (термогравиметрической) и производной от TG функции - ДТG (дифференциальной термогравиметрической) (рис. 7). 
Анализы выполнялись на термоустановке Дериватограф системы F.Paulik, J.Paulik и L.Erdey. Тип прибора - Q -1500Д, фирма "МОМ", Будапешт.

Съемка осуществлялась при следующих условиях: температурный диапазон анализа - 20$1000^{\circ} \mathrm{C}$; режим нагрева - динамический $\left(\frac{d t}{d t}=10\right.$

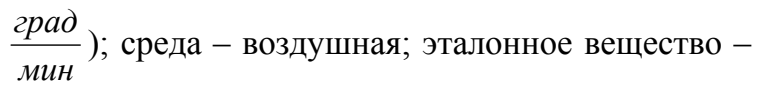
прокаленный $\mathrm{Al}_{2} \mathrm{O}_{3}$; тигли - алундовые; навеска образца -500 мг.

Устанавливалась следующая чувствительность измерительных систем прибора:

$$
\begin{aligned}
& \mathrm{TG}=100 \mathrm{мг}=500 \mu \mathrm{V} ; \\
& \text { ДТА }=250 \mu \mathrm{V} ; \\
& \text { ДТG }=500 \mu \mathrm{V} ; \\
& \mathrm{T}=500 \mu \mathrm{V} .
\end{aligned}
$$

Идентифицирование минералов порошковой пробы проводилось по морфологиям термических кривых и численных значений интенсивностей эндотермических эффектов с использованием сопряженных с ними термогравиметрических показаний TG - линий.

Результаты анализа сравнивались с данными приведенными в атласе термических кривых минералов и горных пород, находящегося в лаборатории термического анализа и сопоставлялись с описаниями термического поведения мономинеральных проб, изложенных в других справочных источниках и накопленных в банке данных лаборатории института геологических наук им. К.И. Сатпаева, где проводились эти исследования.

Результаты термического анализа (рис. 7) показали, что в образце из продуктов коррозии имеются: вода - 2\%, гётит $\mathrm{FeO}(\mathrm{OH})-20,5 \%$, карбонаты $\mathrm{CaCO}_{3}$ и $\mathrm{MgCO}_{3}$ - 4,7\%, гидроксид железа (II) $\mathrm{Fe}(\mathrm{OH})_{2}-4,2 \%$, большое количество магнетита $\mathrm{Fe}_{3} \mathrm{O}_{4}$ и другие вещества в очень малых объемах, которые можно не учитывать. По сравнению с исходным материалом, когда не имеются коррозионные трещины характеристические данные образца из продуктов коррозии, полученные термическим анализом, имеют заниженные значения.

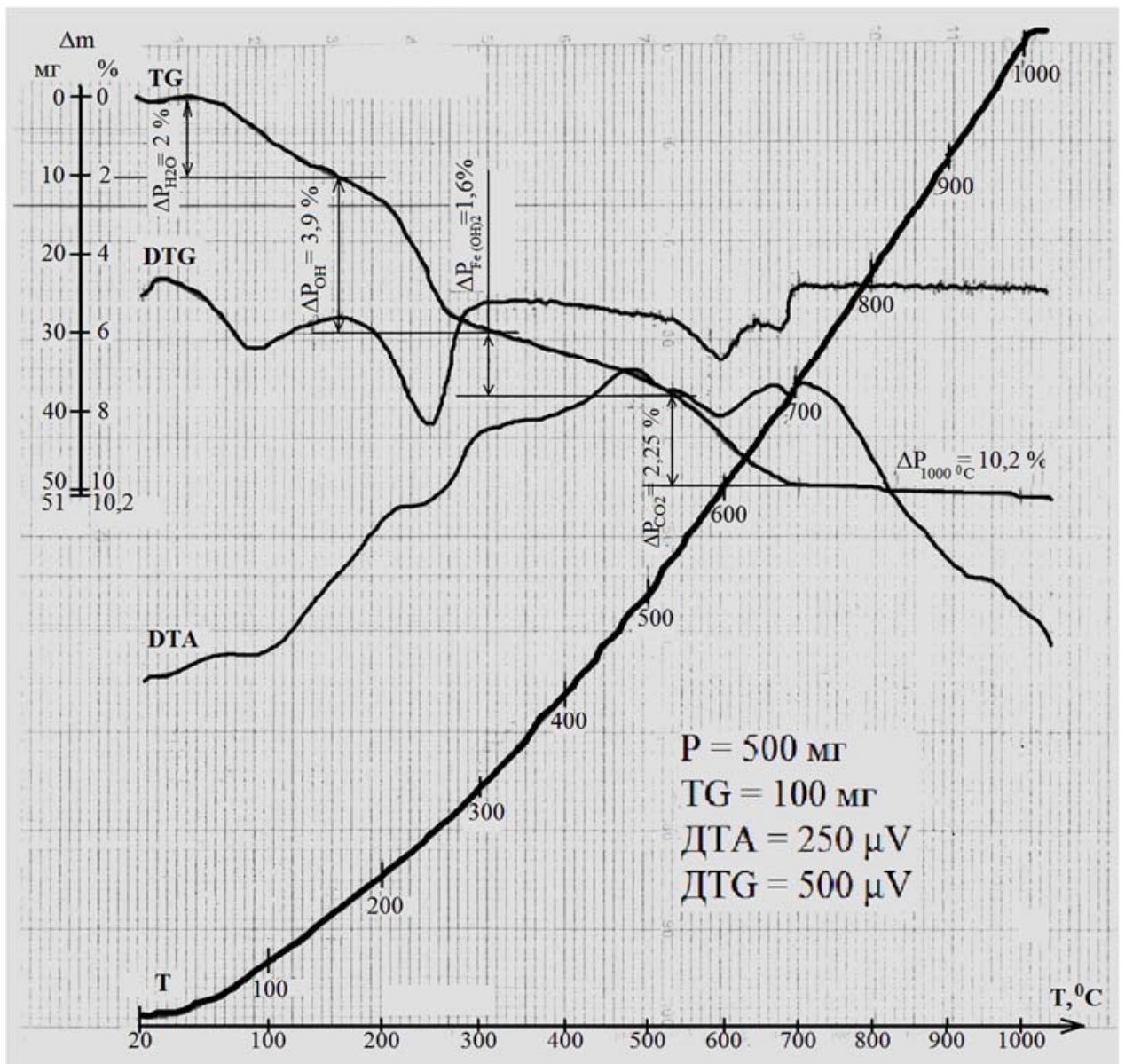

Рисунок 7 - Дериватограмма термического анализа образца из продуктов коррозии. 
Для уточнения предложенного механизма развития коррозии был также проведен рентгенодифрактометрический анализ образца из продуктов коррозии взятого из корродированной поверхности металлических конструкций Ассинского гидроузла.

Рентгенодифрактометрический анализ выполнен на дифрактометре ДРОН-4-07 с $\mathrm{Cu}_{\kappa \alpha}-$ излучением, $\beta$-фильтр, ускоряющее напряжение 35 кВ, ток анода 20 мА.

Количественный рентгенофазовый анализ выполнен по дифрактограммам порошковых проб c применением метода равных навесок и искусственных смесей и использованием значений корундовых чисел минералов из PDF-2.
Определялись количественные соотношения кристаллических фаз.

Интерпретация дифрактограмм проводилась c использованием данных картотеки ASTM (Powder diffraction file) и дифрактограмм чистых от примесей минералов. Для основных фаз проводился расчет содержаний. Возможные примеси, идентификация которых не может быть однозначной из-за малых содержаний и присутствия только 1-2 дифракционных рефлексов или плохой окристаллизованности не указаны на дифрактограмме (рис. 8). Для построения дифрактограммы использовалась данные межплоскостных расстояний и фазовый состав образца (таблица 5).

Таблица 5

Межплоскостные расстояния и фазовый состав образца

\begin{tabular}{|c|c|c|}
\hline $\mathrm{d}, \AA$ & $\mathrm{I}$ & Минерал \\
\hline 4.8465 & 61 & Магнетит \\
\hline 4.2526 & 69 & Гётит, магнетит \\
\hline 3.9862 & 69 & Гётит, магнетит \\
\hline 3.3547 & 68 & Гётит \\
\hline 2.9694 & 75 & Магнетит \\
\hline 2.7097 & 69 & Мётит \\
\hline 2.5225 & 100 & Гётит тит \\
\hline 2.4569 & 70 & Гётит \\
\hline 2.2675 & 64 & Гётит \\
\hline 2.1885 & 65 & Магнетит \\
\hline 2.0894 & 69 & Гётит \\
\hline 1.7061 & 67 & Магнетит \\
\hline 1.6117 & 71 & Магнетит \\
\hline 1.4776 & 71 & . \\
\hline
\end{tabular}

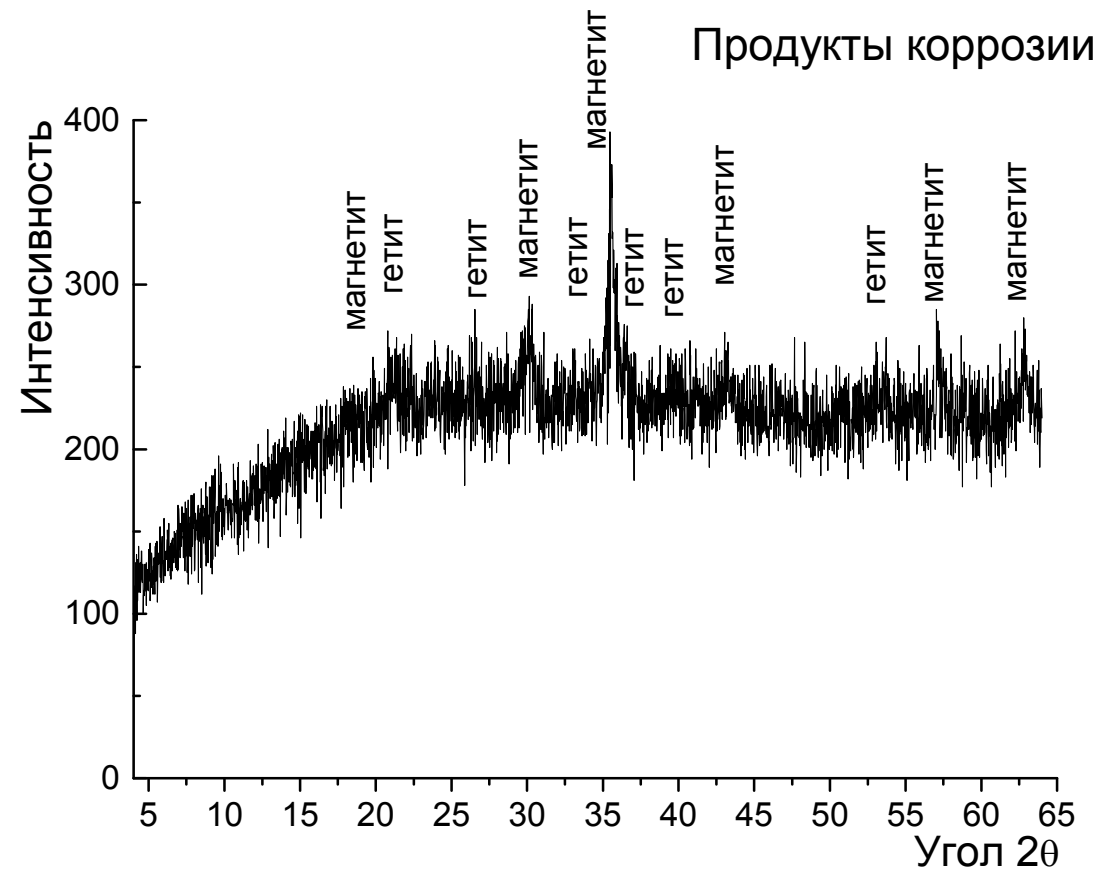

Рисунок 8 - Дифрактограмма образца из продуктов коррозии. 
Завышенный фон рассеяния (65) объясняется высоким содержанием аморфных гидроксидов железа, фазовый состав которых не может быть определен, так как ДРОН-4-07 не предназначен для исследования аморфных фаз.

Результаты количественного рентгенодифрактометрического анализа показали, что в кристаллической фазе исследуемого образца имеются продукты коррозии магнетит $\mathrm{Fe}_{3} \mathrm{O}_{4}-85 \%$, гётит $\mathrm{FeO}(\mathrm{OH})$ $15 \%$, а также определенное количество аморфной фазы. Присутствие магнетита и гётита также подтверждают предложенный механизм развития коррозии, так как магнетит - это одна из форм существования гидроксида железа (III) $\mathrm{Fe}(\mathrm{OH})_{3}$, а гётит является продуктом частичной дегидратации гидроксида железа (III) $\mathrm{Fe}(\mathrm{OH})_{3}$. Рентгенодифракто-метрический анализ подтвердил результаты выполненных ранее рентгеноспектрального микроанализа и термического анализа.

По результатам проведенных химических анализов можно полагать, что обнаружение в образце из продуктов коррозии гидроксида $\mathrm{Fe}_{2} \mathrm{O}_{3}$, гидроксида железа (II) $\mathrm{Fe}(\mathrm{OH})_{2}$, одного из видов существования гидроксида железа (III) $\mathrm{Fe}(\mathrm{OH})_{3}-$ магнетита $\mathrm{Fe}_{3} \mathrm{O}_{4}$ и продукта частичной дегидратации гидроксида железа (III) $\mathrm{Fe}(\mathrm{OH})_{3}$ гётита $\mathrm{FeO}(\mathrm{OH})$ подтвердило положения предложенного механизма развития коррозии.

\section{References:}

1. Evans YR (1941) Korroziya, zashchita i passivnost' metalla. - Moscow: Metallurgizdat, 1941. -124.

2. Tomashov ND (1959) Teoriya korrozii i zashchita metallov. - Moscow: Izd. AN SSSR, 1959. - 592.

3. Karpenko GV (1985) Fiziko-khimicheskaya mekhanika konstruktsionnykh materialov. Izbr.tr. v 2-kh t. - Kiev: Nauk.dumka, 1985.- T. 1. -228 .

4. Ulig GG, Revi RU (1989) Korroziya i bor'ba s ney. Vvedenie $\mathrm{v}$ korrozionnuyu nauku i tekhniku / Pod red. A.M. Sukhotina. - L.: Khimiya, 1989. - 456.

5. Alimbaev BA, Manapbaev BZ (2009) Osobennosti razvitiya korrozii $\mathrm{v}$ elementakh stal'nykh konstruktsiy gidrotekhnicheskikh sooruzheniy // Mat. mezhd. nauch.-prakt. konf.: «Problemy innovatsionnogo razvitiya obshchestva: nastoyashchee i budushchee». Almaty: Evero, 2009. - pp. 91.

6. Alimbaev BA, Manapbaev BZ, Dzhanuzakova RZ (2010) Ob odnom faktore razvitiya korrozii $\mathrm{v}$ elementakh metallicheskikh konstruktsiy gidrotekhnicheskikh sooruzheniy // Mekhanika i modelirovanie protsessov tekhnologii. - Taraz, 2010. - №1. - pp. 116-126.

7. Alimbaev BA, Manapbaev BZ (2012) Razvitie korrozii $\mathrm{V}$ elementakh metallicheskikh konstruktsiy v vodnoy srede. - Taraz: Taraz universiteti, 2012.-136.

8. Akulov NS (1939) Ferromagnetizm. - M.-L.: Gosizdat. tekhnicheskoy i teoreticheskoy literatury, 1939.

9. Gorazdovskiy TY (1977) Nerazrushayushchiy kontrol'.- Moscow: Znanie, - 64.

10. Savel'ev IV (1970) Kurs obshchey fiziki. Elektrichestvo. - Moscow: Nauka, 1970. - T.2. - 432.

11. Stromberg AG, Semchenko DP (2001) Fizicheskaya khimiya. Ucheb. dlya khim. spets. vuzov. Pod redaktsiey A.G.Stromberga. - 4-e izd. ispr. - Moscow: Vyssh. shk., 2001. - 527.

12. Branover GG, Tsinober AB (1970) Magnitnaya gidrodinamika neszhimaemykh sred. - M.: Glavnaya redaktsiya fiziko-matematicheskoy literatury izdatel'stva «Nauka», -380 . 